\title{
Formation of 5-Hydroxy-3-methoxy-1,4-naphthoquinone and 8-Hydroxy-4-methoxy-1,2-naphthoquinone from Juglone
}

\author{
Bastian Blauenburg, ${ }^{1}$ Mikko Metsä-Ketelä, ${ }^{1}$ and Karel D. Klika ${ }^{2}$ \\ ${ }^{1}$ Department of Biochemistry and Food Chemistry, University of Turku, Vatselankatu 2, 20014 Turku, Finland \\ ${ }^{2}$ Department of Chemistry, University of Turku, Vatselankatu 2, 20014 Turku, Finland \\ Correspondence should be addressed to Karel D. Klika, klikakd@yahoo.co.uk
}

Received 25 August 2012; Accepted 12 September 2012

Academic Editors: I. Alonso, N. Farfan, and F. Felluga

Copyright (C) 2012 Bastian Blauenburg et al. This is an open access article distributed under the Creative Commons Attribution License, which permits unrestricted use, distribution, and reproduction in any medium, provided the original work is properly cited.

\begin{abstract}
From the treatment of 5-hydroxy-1,4-naphthoquinone (juglone) with acetic anhydride and $\mathrm{H}_{2} \mathrm{SO}_{4}$ followed subsequently by treatment with methanolic $\mathrm{HCl}$, 5-hydroxy-3-methoxy-1,4-naphthoquinone (3-methoxy juglone) and 8-hydroxy-4-methoxy-1,2naphthoquinone were obtained as products rather than the anticipated product 2,5-dihydroxy-1,4-naphthoquinone (2-hydroxy juglone). The reaction and the identification of the products are discussed in terms of NMR and DFT calculations.
\end{abstract}

\section{Introduction}

As part of our ongoing investigation [1] into the Cribosylation of $(R)$-prealnumycin $(1)$ by AlnA, an enzyme produced by Streptomyces albus (Scheme 1), it was decided to test various 1,4-naphthoquinone substrates against AlnA in order to identify the structural motifs necessary for, or inhibitory to, reaction.

Thus, we considered 2,5-dihydroxy-1,4-naphthoquinone (2, 2-hydroxy juglone, Figure 1) as a test substrate since it could potentially reveal aspects of the charge required to be present on C-3 for the reaction to proceed. Additionally, the facile preparation of 2,5-dihydroxy-7-methyl-1,4naphthoquinone (2-hydroxy-7-methyl juglone, 3) from 5hydroxy-7-methyl-1,4-naphthoquinone (7-methyl juglone, 4) had been reported [2] by treatment first with acetic anhydride and $\mathrm{H}_{2} \mathrm{SO}_{4}$ and then subsequently with methanolic $\mathrm{HCl}$. After treating 5-hydroxy-1,4-naphthoquinone (5, juglone) as prescribed, we obtained not 2-hydroxy juglone (2) as anticipated, but rather 5-hydroxy-3-methoxy-1,4naphthoquinone $(6,3$-methoxy juglone) and 8-hydroxy-4methoxy-1,2-naphthoquinone (7). Mahapatra et al. [2], in turn, seem to have taken their preparation from Lillie and Musgrave [3] who performed precisely the same reaction. Interestingly, whilst the former workers only reported the one product, namely, 2-hydroxy-7-methyl juglone (3), the latter pair reported the formation of both 3 (as the major product) and its regioisomer 3,5-dihydroxy-7-methyl-1,4naphthoquinone (3-hydroxy-7-methyl juglone, 8). Mahapatra et al. [2] only reported ${ }^{1} \mathrm{H}$ NMR chemical shifts $\left(\delta_{\mathrm{H}}\right)$ for their compound, and indeed only one $\mathrm{OH}$ signalwhich they assigned as $\mathrm{HO}-5$ - with no carbon or correlation spectra reported. As best we can ascertain, it appears that Mahapatra et al. [2] based their structural assignment on the work of Lillie and Musgrave [3] and the $\delta_{\mathrm{H}}$ of HO5 (vide infra). This structural assignment therefore carries with it some concern, not because it is a labile proton per $s e$, but rather because of its value in relation to the reported value [3]. The correctness of this structural assignment is scrutinized in this work.

Both 3-methoxy juglone (6) and 8-hydroxy-4-methoxy1,2-naphthoquinone (7) are known compounds, 6 in particular has been studied well synthetically $[4,5]$, is a widely spread naturally occurring compound present, for example, in a number of species of the genus Juglans [6-9], and possesses significant biological activity [7-9]. Compound 7 is unknown outside the laboratory $[4,10,11]$, and overall there are only limited reports on it, though it too has potential biological activity of significance [10]. Herein we report on the synthesis of these two compounds and discuss the reaction and identification of the products in terms of NMR and DFT calculations. 


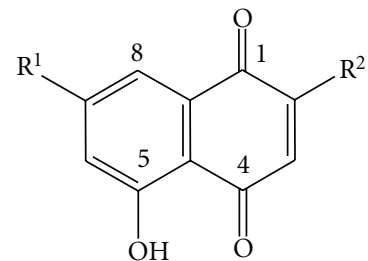

(2) $\mathrm{R}^{1}=\mathrm{H}, \mathrm{R}^{2}=\mathrm{OH}$;

(3) $\mathrm{R}^{1}=\mathrm{CH}_{3}, \mathrm{R}^{2}=\mathrm{OH}$;

(4) $\mathrm{R}^{1}=\mathrm{CH}_{3}, \mathrm{R}^{2}=\mathrm{H}$;

(5) $\mathrm{R}^{1}=\mathrm{H}, \mathrm{R}^{2}=\mathrm{H}$;

(12) $\mathrm{R}^{1}=\mathrm{H}, \mathrm{R}^{2}=\mathrm{CH}_{3} \mathrm{O}$<smiles>[R]C1=CC(=O)c2cc([R])cc(O)c2C1=O</smiles>

(6) $\mathrm{R}^{1}=\mathrm{H}, \mathrm{R}^{2}=\mathrm{OCH}_{3}$;

(8) $\mathrm{R}^{1}=\mathrm{CH}_{3}, \mathrm{R}^{2}=\mathrm{OH}$;

(11) $\mathrm{R}^{1}=\mathrm{H}, \mathrm{R}^{2}=\mathrm{OH}$

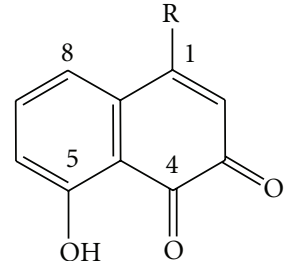

(7) $\mathrm{R}=\mathrm{OCH}_{3}$;

(9) $\mathrm{R}=\mathrm{OH}$

Figure 1: The structures of the 5-hydroxy-1,4-naphthoquinones (juglones) and 8-hydroxy-1,2-naphthoquinones discussed in this work. $\mathrm{Nb}$. For ease of comparison, the atomic numbering of the juglone series is maintained for $\mathbf{7}$ and $\mathbf{9}$ in discussion in the text even though it is unconventional.

\section{Results and Discussion}

Our original intent was to follow analogously the preparation of Mahapatra et al. [2] who reported the synthesis of what they considered to be 2-hydroxy-7-methyl juglone (3) from 7-methyl juglone (4) and apply the same conditions to juglone (5) in order to obtain 2-hydroxy juglone (2). After performing the synthetic preparation, we isolated two major components in comparable amounts and readily identified them as 3-methoxy juglone (6) and 8-hydroxy-4-methoxy1,2-naphthoquinone (7). Whilst fully expecting the first eluting compound from column chromatography over silica gel to be 2-hydroxy juglone (2) rather than 3-methoxy juglone (6), it was immediately evident that a methoxy group was present in the molecule by inspection of the ${ }^{1} \mathrm{H}$ NMR spectrum (see Table 1), and furthermore, its general location was evident from the long-range coupling and an NOE to a vinyl-type proton. Although the methoxy group was then expected to be attached at $\mathrm{C}-2$, the correlation of the vinyl-type proton $(\mathrm{H}-2)$ to $\mathrm{C}-8 \mathrm{a}$ in the $\mathrm{HMBC}$ spectrum was categorical in placing it at $\mathrm{C}-3$ in addition to an NOE between the methoxy group protons and HO-5. Following these pivotal connectivities, the rest of the NMR analysis was consistent with the assigned structure. Turning our intention to the second isolate 7 eluting from the column, it exhibited some strongly divergent NMR spectral differences to 6 (e.g., $\delta_{\mathrm{C} 3}, \delta_{\mathrm{C} 1}$, etc.), and the reason quickly became apparent as this isomer of $\mathbf{6}$ was not a 1,4-quinoid structure, but rather a 1,2-quinoid structure. Notable correlations identifying this compound as 8-hydroxy-4-methoxy-1,2naphthoquinone (7) were $\mathrm{H}-2$ to $\mathrm{C}-8 \mathrm{a}$ and $\mathrm{H}-8$ to C1 (conspicuous by its $\delta_{\mathrm{C}}$ of $168.15 \mathrm{ppm}$ ) in the $\mathrm{HMBC}$ spectrum and the NOE between the methoxy group and H-8.

Though the obtainment of the methoxy derivatives 3-methoxy juglone (6) and 8-hydroxy-4-methoxy-1,2naphthoquinone (7) was unexpected, the presence of methoxy groups may be rationalized simply by methylation of the freed hydroxyls after hydrolysis (Scheme 2). The surprising occurrence of 7 can be accounted for by either of the following: if 4,8-dihydroxy-1,2-naphthoquinone
(9) is not produced directly during the hydrolytic deacetylation concomitant with spontaneous oxidation of the tetraacetylated intermediate $\mathbf{1 0}$, then it arises through prototropic tautomerism from 3,5-dihydroxy1,4-naphthoquinone (3-hydroxy juglone, 11) with which it is in equilibrium with in solution [4]. This has been demonstrated by obtaining 7 as part of a mixture together with 6 when 2-hydroxy juglone (2) is methylated [4]. Given the results of our reaction together with those of Mahapatra et al. [2] and Lillie and Musgrave [3], it seems that despite the deceptive simplicity of the reaction, it can be highly variable in terms of regiospecificity since sometimes attack at C-2 dominates [3], sometimes attack occurs exclusively at C-3 (this work), or sometimes attack seemingly occurs exclusively at C-2 [2] (vide infra).

To first address the question of regiospecificity, DFT calculations revealed that 2-hydroxy juglone (2) is $1.40 \mathrm{kcal} \mathrm{mol}^{-1}$ more stable than 3-hydroxy juglone (11), similar results were obtained for 2-hydroxy-7-methyl juglone (3, $\left.0.00 \mathrm{kcal} \mathrm{mol}^{-1}\right)$ and 3-hydroxy-7-methyl juglone (8, $\left.1.24 \mathrm{kcal} \mathrm{mol}^{-1}\right)$ in consideration of the work of Mahapatra et al. [2] and Lillie and Musgrave [3], and furthermore, similar results were also obtained for 2-methoxy juglone (12, $\left.0.00 \mathrm{kcal} \mathrm{mol}^{-1}\right)$ and 3-methoxy juglone $\left(6,0.66 \mathrm{kcal} \mathrm{mol}^{-1}\right)$ in consideration of the methoxy derivatives isolated in this study. Thus, in each case, the 2-substituted derivative was calculated to be the thermodynamic product, which is consistent with the results of Mahapatra et al. [2] and Lillie and Musgrave [3] but does not account for the observations herein. To consider if the $\mathrm{C}-2$ position was more susceptible to nucleophilic attack, the atomic charges on C-2 and C-3 were examined: in juglone (5), the Mulliken charge on C-2, $Q_{\mathrm{C} 2}$, was calculated to be $-0.182 \mathrm{cf}$. $Q_{\mathrm{C} 3}$ at -0.176 . These differences did not differ appreciably for 7 -methyl juglone (4) where charges of -0.184 and -0.175 , respectively, were found for $Q_{\mathrm{C} 2}$ and $Q_{\mathrm{C} 3}$. These charge differences are considered inconsequential to the course of the reaction, either between 2 - and 3-substituted products or for differences observed between 7-methyl juglone (4) and juglone (5). 


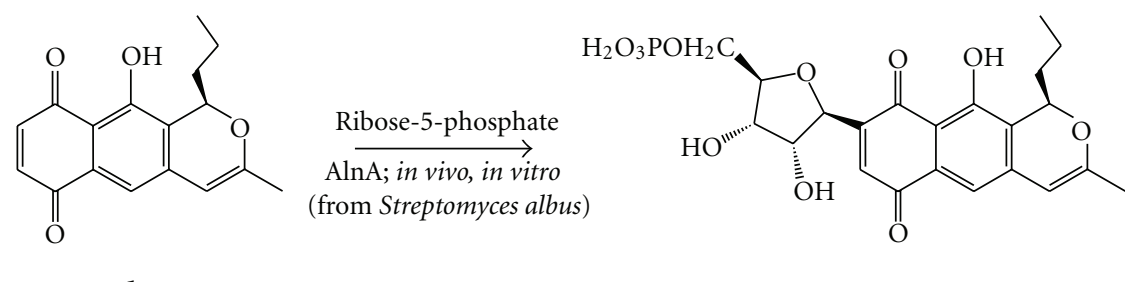

1

Scheme 1: The C-ribosylation of (R)-prealnumycin (1) by Streptomyces albus.<smiles>CC(=O)Oc1cc(OC(C)=O)c2cccc(OC(C)=O)c2c1OC(C)=O</smiles><smiles>O=C1C=C(O)C(=O)c2c(O)cccc2C1=O</smiles>

Scheme 2: The reaction sequence from juglone (5) leading to the isomeric 3-methoxy juglone (6) and 8-hydroxy-4-methoxy-1,2naphthoquinone (7).

Kinetically however, it would appear that, based on the energetic preference by $5.24 \mathrm{kcal} \mathrm{mol}^{-1}$ for the intermediate in the case of attack by acetic anhydride on protonated juglone $(\mathbf{5 H})$ at the $\mathrm{C}-3$ position over the $\mathrm{C}-2$ position (Scheme 3), 3-hydroxy juglone (11) would be the preferred product after oxidative hydrolysis. Interestingly, attack by acetate to yield the enolate ion provides the opposite effect, and then some with attack at the C-2 position preferred over the C-3 position by $9.39 \mathrm{kcal} \mathrm{mol}^{-1}$; that is, 2-hydroxy juglone (2) would be expected as the preferred end-product. Since the reaction was conducted under acid-catalyzed conditions and is likely to be irreversible, it is concluded that 3-hydroxy juglone (11) should be the dominant product, essentially in concert with observations in this work since 3 -substituted products ( 6 and 7 ) were obtained. Kinetically one can anticipate similar results for 7-methyl juglone (4) as for the reaction of juglone (5). However it is clear that there must be a fine balance between the competing pathways, and even slight perturbation of the conditions could lead to very different results being obtained.
To gain further insight into these structures, DFT calculations of their ${ }^{1} \mathrm{H}$ and ${ }^{13} \mathrm{C}$ NMR chemical shifts $\left(\delta_{\mathrm{H}} \mathrm{S}\right.$ and $\delta_{C}$ s, resp.) were performed (see Table 2) as these have proven to be of considerable assistance in structural analysis [14-16]. Interestingly, there is nothing in the calculated $\delta_{\mathrm{H}} \mathrm{s}$ of the nonlabile protons in 2-hydroxy juglone (2) and 3hydroxy juglone (11) to categorically distinguish between the two structures. The same holds for the calculated $\delta_{\mathrm{H}} \mathrm{S}$ of the nonlabile protons in 2-hydroxy-7-methyl juglone (3) and 3-hydroxy-7-methyl juglone (8) and for the methoxy derivatives 2-methoxy juglone (12) and 3-methoxy juglone (6), with the latter pair even more similar. Thus, to reliably distinguish between the two compounds in any of these pairs based on the $\delta_{\mathrm{H}} \mathrm{s}$ of the nonlabile protons, one must be in possession of both compounds. The exception is for the exchangeable HO-5 protons where significant differences are clearly evident. Usually though, labile protons are considered unreliable for assignment purposes based on experimental $\delta_{\mathrm{H}}$ however, the experimental $\delta_{\mathrm{H}}$ of $\mathrm{OH}$ protons can, if certain conditions are met, namely conditions conducive to slow exchange of the protons, be treated as reliable for 
TABle 1: ${ }^{1} \mathrm{H}$ and ${ }^{13} \mathrm{C}$ NMR data for 3-methoxy juglone (6) and 8-hydroxy-4-methoxy-1,2-naphthoquinone (7) in $\mathrm{CDCl}_{3}$ at $25^{\circ} \mathrm{C}$.

\begin{tabular}{|c|c|c|c|c|c|c|c|c|}
\hline \multirow{3}{*}{ Pos. } & \multicolumn{4}{|c|}{ 3-Methoxy juglone (6) } & \multicolumn{4}{|c|}{ 8-Hydroxy-4-methoxy-1,2-naphthoquinone (7) } \\
\hline & \multicolumn{2}{|c|}{$\delta^{\mathrm{a}} / \mathrm{ppm}$} & \multirow{2}{*}{ Multiplicity } & \multirow{2}{*}{$J\left({ }^{1} \mathrm{H},{ }^{1} \mathrm{H}\right)^{\mathrm{b}, \mathrm{c}} / \mathrm{Hz}$} & \multicolumn{2}{|c|}{$\delta^{\mathrm{a}} / \mathrm{ppm}$} & \multirow{2}{*}{ Multiplicity } & \multirow{2}{*}{$J\left({ }^{1} \mathrm{H},{ }^{1} \mathrm{H}\right)^{\mathrm{b}, \mathrm{d}} / \mathrm{Hz}$} \\
\hline & ${ }^{13} \mathrm{C}$ & ${ }^{1} \mathrm{H}^{\mathrm{b}}$ & & & ${ }^{13} \mathrm{C}$ & ${ }^{1} \mathrm{H}^{\mathrm{b}}$ & & \\
\hline 1 & 183.95 & - & & & 168.15 & - & & \\
\hline 2 & 110.50 & 6.160 & qt & $-0.41(\mathrm{O}-\mathrm{Me})$ & 103.00 & 5.955 & s & $\begin{array}{c}0.35(\mathrm{O}-\mathrm{Me}), 0.23(\mathrm{H}-8) \\
0.18(\mathrm{H}-6)\end{array}$ \\
\hline 3 & 160.08 & - & & & 179.06 & - & & \\
\hline 4 & 184.94 & - & & & 182.97 & - & & \\
\hline $4 a$ & 114.28 & - & & & 113.87 & - & & \\
\hline 5 & 161.98 & 11.750 & dist. $\mathrm{d}$ & $0.43(\mathrm{H}-7), 0.03(\mathrm{H}-6)$ & 164.87 & 12.057 & $\mathrm{~d}$ & $0.48(\mathrm{H}-7)$ \\
\hline 6 & 123.87 & 7.246 & ho $\mathrm{m}$ & $\begin{array}{c}8.48(\mathrm{H}-7), 1.09(\mathrm{H}-8) \\
0.03(\mathrm{HO}-5)\end{array}$ & 122.43 & 7.138 & ddd & $\begin{array}{c}8.61(\mathrm{H}-7), 1.01(\mathrm{H}-8) \\
0.18(\mathrm{H}-2)\end{array}$ \\
\hline 7 & 137.20 & 7.640 & ho $\mathrm{m}$ & $\begin{array}{c}8.48(\mathrm{H}-6), 7.45(\mathrm{H}-8) \\
0.43(\mathrm{HO}-5)\end{array}$ & 138.14 & 7.588 & ddd & $\begin{array}{c}8.61(\mathrm{H}-6), 7.54(\mathrm{H}-8) \\
0.48(\mathrm{HO}-5)\end{array}$ \\
\hline 8 & 118.95 & 7.630 & ho $\mathrm{m}$ & 7.45 (H-7), 1.09 (H-6) & 117.51 & 7.411 & ddd & $\begin{array}{c}7.54(\mathrm{H}-7), 1.01(\mathrm{H}-6) \\
0.23(\mathrm{H}-2)\end{array}$ \\
\hline $8 a$ & 132.06 & - & & & 131.81 & - & & \\
\hline $\mathrm{CH}_{3} \mathrm{O}$ & 56.61 & 3.920 & d & $-0.41(\mathrm{H}-2)$ & 56.83 & 3.994 & $\mathrm{~d}$ & $0.35(\mathrm{H}-2)$ \\
\hline
\end{tabular}

d: doublet; dist.: distorted; ho: higher order; m: multiplet; qt: quartet; s: singlet. ${ }^{\text {al }} \mathrm{H}$ and ${ }^{13} \mathrm{C}$ spectra referenced internally to TMS $(\delta=0.00 \mathrm{ppm}$ for both nuclei). ${ }^{b}$ Chemical shifts and coupling constants extracted using the Perch simulation software $[12,13] .{ }^{c}$ Couplings in the aromatic ring were determined to be positive from higher-order analysis and were consistent with signs from DFT calculations except for ${ }^{4} J_{\mathrm{H} 6, \mathrm{HO} 5}$ which was also found to be positive by spin simulation. Despite its small value, ${ }^{4} J_{\mathrm{H} 6, \mathrm{HO} 5}$ was evident in the lineshape. ${ }^{5} \mathrm{~J}_{\mathrm{H} 2, \mathrm{OMe}}$ determined to be negative by DFT calculations. ${ }^{\mathrm{d} 4} \mathrm{~J}_{\mathrm{H} 6, \mathrm{H} 8}$ and ${ }^{5} J_{\mathrm{HO}}, \mathrm{H} 7$ were set positive in analogy with 6 and were consistent with signs from DFT calculations. Signs of ${ }^{5} J_{\mathrm{H} 2, \mathrm{H} 8},{ }^{5} J_{\mathrm{H} 2, \mathrm{OMe}}$, and ${ }^{7} J_{\mathrm{H} 2, \mathrm{H} 6}$ assigned by DFT calculations.<smiles>O=C1C=CC(=O)c2c(O)cccc21</smiles><smiles>CCOC(C)=O</smiles>

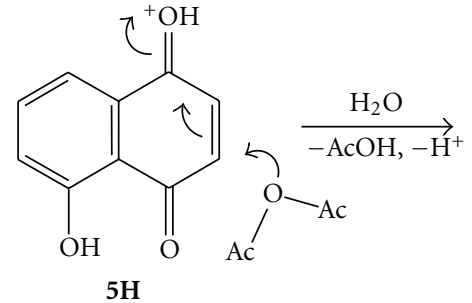

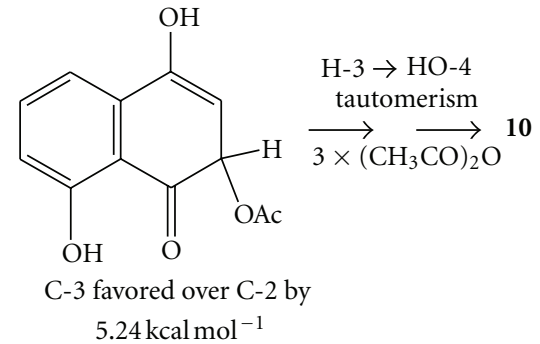

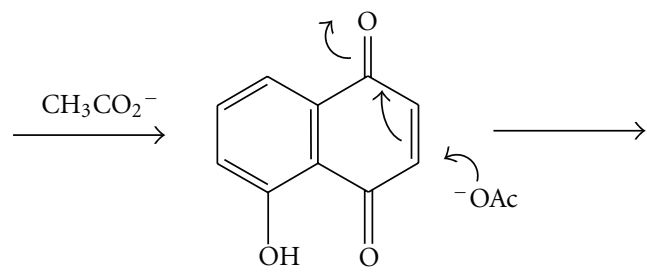<smiles>CC(=O)OC1C=C([O-])c2cccc(O)c2C1=O</smiles>

C-2 favored over $\mathrm{C}-3$ by $9.39 \mathrm{kcal} \mathrm{mol}^{-1}$

Scheme 3: Intermediates resulting from attack by acetic anhydride/ $\mathrm{H}^{+}$or acetate ion.

assignment purposes [3]. With respect to calculated $\delta_{\mathrm{H}} \mathrm{S}$, although the chemical shifts of labile protons are generally problematic to calculate in absolute terms, they are normally reliably found in their correct chemical shift order. When exchangeable protons are strongly hydrogen bonded though, they can be accurately calculated, and this is clearly evident in the case of 2 and 11 (experimental values of $12.28 \mathrm{ppm}$ and $11.04 \mathrm{ppm}$, resp. [3]) and for $\mathbf{6}$. Thus, HO-5 is the only proton with a decisive indication of isomer identification in these pairs of compounds.

Mahapatra et al. [2] only observed one $\mathrm{OH}$ signal, assigned as the HO-5 proton, in which case the other $\mathrm{OH}$ signal must therefore be broad due to exchange despite the possibility of it too being intramolecularly hydrogen bonded. Therefore, under such conditions the $\delta_{\mathrm{H}}$ reliability of the observed $\mathrm{OH}$ proton must be treated with caution. However, 
TABLE 2: DFT-calculated ${ }^{1} \mathrm{H}$ NMR $\delta_{\mathrm{H}} \mathrm{s}$ (ppm) for compounds $2, \mathbf{3}, \mathbf{6}, \mathbf{8}, \mathbf{1 1}$, and 12.

\begin{tabular}{|c|c|c|c|c|c|c|}
\hline Compound & $\mathrm{H}-2 / \mathrm{HO}-2 / \mathrm{CH}_{3} \mathrm{O}-2$ & $\mathrm{H}-3 / \mathrm{HO}-3 / \mathrm{CH}_{3} \mathrm{O}-3$ & $\mathrm{HO}-5$ & $\mathrm{H}-6$ & $\mathrm{H}-7 / \mathrm{CH}_{3}-7$ & $\mathrm{H}-8$ \\
\hline 2-Hydroxy juglone (2) & 7.62 & 6.06 & 12.33 & 7.26 & 7.45 & 7.76 \\
\hline 3-Hydroxy juglone (11) & 6.09 & 7.42 & 11.04 & 7.11 & 7.59 & 7.77 \\
\hline 2-Hydroxy-7-methyl juglone (3) & 7.57 & 6.03 & 12.34 & 7.05 & 2.38 & 7.62 \\
\hline 3-Hydroxy-7-methyl juglone (8) & 6.05 & 7.44 & 11.05 & 6.91 & 2.40 & 7.62 \\
\hline 3, observed [2] & no & 6.08 & 11.69 & 7.01 & 2.41 & 7.42 \\
\hline 2-Methoxy juglone (12) & 3.68 & 5.78 & 12.19 & 7.17 & 7.45 & 7.72 \\
\hline 3-Methoxy juglone (6) & 5.80 & 3.69 & 11.76 & 7.11 & 7.51 & 7.73 \\
\hline 6, observed (this work) & 6.16 & 3.92 & 11.75 & 7.25 & 7.64 & 7.63 \\
\hline
\end{tabular}

Legend: no: not observed.

one inference can be made: the reported [2] value for $\delta_{\mathrm{HO}}$, $11.69 \mathrm{ppm}$, is intermediate between $\delta_{\mathrm{HO} 5}$ values reported [3] for 2-hydroxy-7-methyl juglone (3), $12.23 \mathrm{ppm}$, and 3hydroxy-7-methyl juglone $(\mathbf{8}), 10.99 \mathrm{ppm}$. If a mixture of $\mathbf{3}$ and $\mathbf{8}$ was present, then the observed intermediate value may be a consequence of intermolecular proton exchange. Of note, exchange can be appreciable on the NMR timescale at the observational frequency of $200 \mathrm{MHz}$ used by Mahapatra et al. [2]. A mixture of $\mathbf{3}$ and $\mathbf{8}$ would also exhibit a depressed m.p., and indeed a depressed m.p. of $10^{\circ} \mathrm{C}$ below that of the lower melting point isomer $\mathbf{3}$ was in fact reported [2] by them. Since there are insufficient differences in the calculated $\delta_{\mathrm{H}} \mathrm{s}$ of the nonlabile protons to decisively affect isomer identification of the pure compounds with only one isomer on hand, one cannot conclude from the reported [2] $\delta_{\mathrm{H}} \mathrm{s}$ which compound(s) was present in the sample. Indeed, for a mixture, differences might only be seen with decent resolution which could easily be lost by even slightly poor $B_{0}$ field homogeneity and which would be problematic in any case at $200 \mathrm{MHz}$. Mahapatra et al. [2] only described H-6 and H-8 as singlets, whilst we observed multiplets for the analogous protons in 7-methyl juglone (4). Furthermore, they did not do more to determine which compound they had or even if they had a mixture of compounds (e.g., IR and HRMS are insufficient for this purpose in the current case). Therefore, although we cannot unequivocally confirm that Mahapatra et al. [2] have the wrong structure(s) for the compound they claim as 2-hydroxy-7-methyl juglone, we must conclude that they had, most probably, a mixture of 3 and 8.

The DFT-calculated ${ }^{13} \mathrm{C}$ NMR chemical shifts are presented in Table 3 wherein it can be seen that for each isomeric pair, four carbons are able to provide substantial differentiation for assignment purposes. There is clearly no problem in identifying our 3-methoxy juglone (6) as the correct structure based on comparison of the calculated $\delta_{\mathrm{C}} \mathrm{s}$ for 2-methoxy juglone (12) and 6, in particular, $\delta_{\mathrm{C} 1}, \delta_{\mathrm{C} 4}$, and $\delta_{\mathrm{C} 7}$. Even assignment is not necessary as $\delta_{\mathrm{C} 6}, \delta_{\mathrm{C} 7}$, and $\delta_{\mathrm{C} 8}$ are all well dispersed from one another so one only needs to look for chemical shift differences $(\Delta \delta)$ in the appropriate region. Of special note though is the $\Delta \delta$ between $\delta_{\mathrm{C} 1}$ and $\delta_{\mathrm{C} 4}$, which has been calculated as $11.02 \mathrm{ppm}$ for $\mathbf{1 2}$ whilst for $\mathbf{6}$ it is $2.65 \mathrm{ppm}$ the latter comparing rather well to the observed value of $0.99 \mathrm{ppm}$. At the very least, ${ }^{13} \mathrm{C}$ NMR acquisition, if not affording isomer identification (correlation spectra notwithstanding) outright, readily alludes to the presence of isomers in a sample and should have been the method of choice in the study of Mahapatra et al. [2].

\section{Conclusions}

The treatment of 5-hydroxy-1,4-naphthoquinone (5, juglone) with acetic anhydride under acidic conditions can lead to variable results as the course of the reaction is very dependent on the exact conditions applied. Herein the treatment of juglone (5) with acetic anhydride and $\mathrm{H}_{2} \mathrm{SO}_{4}$ and then subsequent treatment with methanolic $\mathrm{HCl}$ led to the isomeric compounds 5-hydroxy-3-methoxy-1,4naphthoquinone (6, 3-methoxy juglone) and 8-hydroxy-4methoxy-1,2-naphthoquinone (7) being obtained instead of the desired 2-hydroxy juglone (2). To correctly identify the products of a reaction in which regiospecificity may be variable or lacking altogether, it is important that appropriate analytical methods be applied, for example, ${ }^{13} \mathrm{C}$ NMR, correlation spectra, or molecular modeling, to properly identify isomers or at least ascertain the presence of other isomers in the sample. In the case of comparison to the literature data, care needs to be taken that conditions are compliant with the measurements being undertaken to ensure correct interpretation of the results. Certainly, reliance on more than just one $\delta_{\mathrm{H}}$ value for identification should be exercised for the dangers of not doing so are self-evident.

\section{Experimental}

4.1. NMR. NMR spectra were acquired using a Bruker Avance NMR spectrometer equipped with either a $5 \mathrm{~mm}$ inverse or a $5 \mathrm{~mm}$ normal configuration probe, both with z-gradient capability, at a field strength of $11.75 \mathrm{~T}$ operating at 500 and $125 \mathrm{MHz}$ for ${ }^{1} \mathrm{H}$ and ${ }^{13} \mathrm{C}$ nuclei, respectively, at $25^{\circ} \mathrm{C}$ with samples contained in $\mathrm{CDCl}_{3}$. The chemical shifts of ${ }^{1} \mathrm{H}$ and ${ }^{13} \mathrm{C}$ nuclei are reported relative to TMS incorporated as an internal standard $(\delta=0 \mathrm{ppm}$ for both ${ }^{1} \mathrm{H}$ and ${ }^{13} \mathrm{C}$ ). General NMR experimental details for $1 \mathrm{D}{ }^{1} \mathrm{H}$, ${ }^{13} \mathrm{C}$, and DEPT and standard gradient-selected 2D DQFCOSY, HSQC, and HMBC spectra have been previously described [17-20] for routine structural determinations 
TABle 3: DFT-calculated ${ }^{13} \mathrm{C}$ NMR chemical shifts (ppm) for compounds $\mathbf{2}, \mathbf{3}, \mathbf{6}, \mathbf{8}, \mathbf{1 1}$, and 12.

\begin{tabular}{lccccccccccc}
\hline Compound & C-1 & C-2 & C-3 & C-4 & C-4a & C-5 & C-6 & C-7 & C-8 & C-8a & CH 3 \\
\hline 2-Hydroxy juglone (2) & 181.93 & 156.99 & 107.41 & 190.08 & 112.87 & 163.49 & 127.36 & 133.75 & 118.07 & 129.19 & - \\
3-Hydroxy juglone (11) & 181.77 & 108.35 & 156.87 & 185.51 & 111.33 & 163.53 & 121.69 & 138.31 & 118.51 & 132.99 & - \\
2-Hydroxy-7-methyl juglone (3) & 182.16 & 156.97 & 107.50 & 189.51 & 110.56 & 163.81 & 126.85 & 147.59 & 118.88 & 128.95 & 19.63 \\
3-Hydroxy-7-methyl juglone (8) & 182.07 & 108.00 & 157.30 & 184.36 & 109.37 & 163.93 & 121.10 & 152.92 & 119.59 & 133.35 & 20.78 \\
2-Methoxy juglone (12) & 178.88 & 162.04 & 106.98 & 189.90 & 112.93 & 163.45 & 124.69 & 134.41 & 117.97 & 131.52 & 51.86 \\
3-Methoxy juglone (6) & 181.91 & 107.32 & 161.80 & 184.56 & 112.91 & 163.95 & 122.57 & 136.40 & 117.42 & 131.94 & 51.74 \\
6, observed (this work) & 183.95 & 110.50 & 160.08 & 184.94 & 114.28 & 161.98 & 123.87 & 137.20 & 118.95 & 132.06 & 56.61 \\
\hline
\end{tabular}

and chemical shift assignments. For 1D selective COSY (set on a $J$ value of $7 \mathrm{~Hz}$ for vicinal coupling whilst for long-range $J$, values varied in the range $0.25-1 \mathrm{~Hz}$ ) and NOESY $[21,22]$ (mixing times: $0.5,0.75 \mathrm{~s}$ ) experiments, selective excitation was effected using a $180^{\circ} 50 \mathrm{~ms}$ Gaussian-shaped pulse via excitation sculpting [23]. Spin analysis was performed using the Perch iteration software $[12,13]$ for the extraction of $\delta_{\mathrm{H}}$ and $J_{\mathrm{H}, \mathrm{H}}$.

4.2. Molecular Modeling. DFT quantum chemical calculations were performed using Gaussian 09 [24] (version A.01) and analyzed using GaussView (version 3.07). Geometry optimization of the structures in the gas phase was performed using the M06-2X hybrid metadensity functional $[25,26]$ with the $6-31 G(d)$ basis set in tandem with vibrational analysis and thermochemistry calculations at the same level of theory. Vibrational analyses, invoking the keyword freq $=$ noraman, were conducted to confirm that optimized structures were true minima on the potential energy surface by not providing imaginary frequencies and to obtain the thermodynamic contributions at $298.15 \mathrm{~K}$ and $1 \mathrm{~atm}$ wherein frequencies were left unscaled. If necessitated by the presence of imaginary frequencies, structures were re-optimized (together also with vibrational analyses and thermochemistry calculations) using tight convergence criteria by invoking the keywords opt $=$ tight and int $=$ ultrafine.

Absolute chemical shieldings were calculated for geometry-optimized structures in the gas phase using the GIAO method [27] and the B3LYP functional [28, 29] with the cc-pVTZ basis set. Chemical shifts were determined by subtracting calculated shieldings from the calculated shieldings of the reference compound TMS for which both $\delta_{\mathrm{H}}$ and $\delta_{\mathrm{C}}=0.00 \mathrm{ppm}$. The chemical shifts of ${ }^{1} \mathrm{H}$ and ${ }^{13} \mathrm{C}$ nuclei were calibrated following literature methodology [17] using the following relationships:

$$
\begin{aligned}
& \delta_{\mathrm{H}}=0.9736 \times \delta_{\text {calc }}+0.058\left(R^{2}=0.9970\right), \\
& \delta_{\mathrm{C}}=0.9880 \times \delta_{\text {calc }}-3.780\left(R^{2}=0.9987\right) .
\end{aligned}
$$

4.3. Synthetic Preparation of 3-Methoxy Juglone (6) and 8Hydroxy-4-methoxy-1,2-naphthoquinone (7). Following the method of Mahapatra et al. [2], a mixture of juglone $(0.6 \mathrm{mmol})$, acetic acid anhydride $(3 \mathrm{~mL})$, and concentrated $\mathrm{H}_{2} \mathrm{SO}_{4}(0.1 \mathrm{~mL})$ was kept overnight and then poured onto ice. The reaction mixture was extracted with chloroform, dried with $\mathrm{MgSO}_{4}$, and then filtered. The residue obtained after removal of the solvent in vacuo was crystallized from chloroform-hexane and the solid material collected by filtration, taken up in methanolic $\mathrm{HCl}(2 \mathrm{M})$, and then refluxed for 1 hour. After extraction of the compound using diethyl ether, column chromatography over silica gel $\left(\mathrm{CHCl}_{3}-\mathrm{CH}_{3} \mathrm{OH}, 95: 5\right)$ resulted in early fractions containing 6 followed by later fractions containing 7. Analysis of the reaction products was accomplished by HPLC (SunFire C18 $3.5 \mu \mathrm{m}, 2.1 \times 150 \mathrm{~mm}$ ) equipped with a UV-Vis DAD and using a gradient of $15-100 \%$ acetonitrile in water with $0.1 \%$ formic acid whereby 7 was found to elute before 6 . Both compounds were subjected to semipreparative HPLC (SunFire Prep C18 $5 \mu \mathrm{m}, 10 \times 250 \mathrm{~mm}$ ) for final purification using the same gradient of $15-100 \%$ acetonitrile in water with $0.1 \%$ formic acid. UV-Vis: for $6, \lambda_{\max } 281,411 \mathrm{~nm}$; for 7, $\lambda_{\max } 286,422 \mathrm{~nm}$. For ${ }^{1} \mathrm{H}$ and ${ }^{13} \mathrm{C}$ NMR data of 6 and 7, see Table 1 .

\section{Acknowledgments}

The Academy of Finland (Grant nos. 136060 and 251486) is thanked for financial support and the CSC-IT Center for Science Ltd. is thanked for providing computational resources.

\section{References}

[1] T. Oja, K. D. Klika, L. Appassamy et al., "Biosynthetic pathway toward carbohydrate-like moieties of alnumycins contains unusual steps for $\mathrm{C}-\mathrm{C}$ bond formation and cleavage," Proceedings of the National Academy of Sciences of the United States of America, vol. 109, no. 16, pp. 6024-6029, 2012.

[2] A. Mahapatra, S. P. N. Mativandlela, B. Binneman et al., "Activity of 7-methyljuglone derivatives against Mycobacterium tuberculosis and as subversive substrates for mycothiol disulfide reductase," Bioorganic and Medicinal Chemistry, vol. 15, no. 24, pp. 7638-7646, 2007.

[3] T. J. Lillie and O. C. Musgrave, "Ebenaceae extractives. Part 7. Use of hydroxy-proton shifts of juglone derivatives in structure elucidation," Journal of the Chemical Society, Perkin Transactions 1, no. 4, pp. 355-359, 1977.

[4] H. Laatsch, "Methylation of 3,3'-dihydroxylated 2,2'-binaphtho-1,4;1',4' -quinones," Zeitschrift für Naturforschung $B$, vol. 45, no. 3, pp. 393-400, 1990.

[5] G. Wurm and U. Geres, "1,4-Naphthoquinones, XVII: studies on the synthesis of 3-hydroxy-juglone derivatives," Archiv der Pharmazie, vol. 322, no. 3, pp. 155-157, 1989. 
[6] H.-Y. Yu, X. Li, F.-Y. Meng, H.-F. Pi, P. Zhang, and H.-L. Ruan, "Naphthoquinones from the root barks of Juglans cathayensis Dode," Journal of Asian Natural Products Research, vol. 13, no. 7, pp. 581-587, 2011.

[7] H. Ruan and H. Yu, "Application of two naphthoquinone compounds in preparing the medical preparations for treating neoplasm," Chinese Patent, CN 102552226 A 20120711, 2012.

[8] W. Tang and F. Chen, "Preparation of antitumor agent from Juglans regia," Chinese Patent, CN 101185671 A 20080528, 2008.

[9] M.-1. Sun, Z.-q. Song, and G.-z. Fang, "Antifungal activities and active components of alcoholic extracts from leaves of Juglans mandshurica Maxim," Linchan Huaxue Yu Gongye, vol. 27, pp. 81-84, 2007.

[10] K. Ditrich, G. Hamprecht, E. Ammermann, G. Lorenz, and H. Laatsch, "Preparation of 1,2-naphthoquinones as fungicides," German Patent, DE 3926747 A1 19910214, 1991.

[11] G. Wurm and U. Geres, "1,4-Naphthoquinones, X: reactions of the methyl ethers of 1,5-dihydroxynaphthalene with singlet oxygen," Archiv der Pharmazie, vol. 318, no. 10, pp. 931-937, 1985.

[12] Peak Research NMR Software, Perch Solutions, Kuopio, Finland, 2003, http://www.perchsolutions.com.

[13] R. Laatikainen, M. Niemitz, U. Weber, J. Sundeun, T. Hassinen, and J. Vepsäläinen, "General strategies for totallineshape-type spectral analysis of NMR spectra using integral-transform iterator," Journal of Magnetic Resonance, Series A, vol. 120, no. 1, pp. 1-10, 1996.

[14] S. Böhm, J. Tomaščiková, J. Imrich et al., "Computational study to assign structure, tautomerism, E/Z and s-cis/s-trans isomerism, $\pi$-delocalization, partial aromaticity, and the ring size of 1,3-thiazolidin-4-ones and 1,3-thiazin-4-ones formed from thiosemicarbazides," Journal of Molecular Structure, vol. 916, no. 1-3, pp. 105-118, 2009.

[15] P. Tähtinen, A. Bagno, K. D. Klika, and K. Pihlaja, "Modeling NMR parameters by DFT methods as an aid to the conformational analysis of cis-fused $7 \mathrm{a}(8 \mathrm{a})$-methyl octa(hexa)hydrocyclopenta[d][1,3] oxazines and [3,1]benzoxazines," Journal of the American Chemical Society, vol. 125, no. 15, pp. 4609-4618, 2003.

[16] K. Pihlaja, P. Tähtinen, K. D. Klika, T. Jokela, A. Salakka, and K. Wähälä, "Experimental and DFT ${ }^{1} \mathrm{H}$ NMR study of conformational equilibria in trans-4',7-dihydroxyisoflavan$4^{\prime}$-ol and trans-isoflavan-4-ol," Journal of Organic Chemistry, vol. 68, no. 18, pp. 6864-6869, 2003.

[17] J. Mäki, P. Tähtinen, L. Kronberg, and K. D. Klika, "Restricted rotation/tautomeric equilibrium and determination of the site and extent of protonation in bi-imidazole nucleosides by multinuclear NMR and GIAO-DFT calculations," Journal of Physical Organic Chemistry, vol. 18, no. 3, pp. 240-249, 2005.

[18] P. Virta, A. Koch, M. U. Roslund et al., "Synthesis, characterisation and theoretical calculations of 2,6-diaminopurine etheno derivatives," Organic and Biomolecular Chemistry, vol. 3, no. 16, pp. 2924-2929, 2005.

[19] K. D. Klika, J. Bernát, J. Imrich, I. Chomča, R. Silanpää, and K. Pihlaja, "Unexpected formation of a spiro acridine and fused ring system from the reaction between an $\mathrm{N}$ acridinylmethyl-substituted thiourea and bromoacetonitrile under basic conditions," Journal of Organic Chemistry, vol. 66, no. 12 , pp. 4416-4418, 2001.

[20] E. Balentová, J. Imrich, J. Bernát et al., "Stereochemistry, tautomerism, and reactions of acridinyl thiosemicarbazides in the synthesis of 1,3-thiazolidines," Journal of Heterocyclic Chemistry, vol. 43, no. 3, pp. 645-656, 2006.
[21] J. Stonehouse, P. Adell, J. Keeler, and A. J. Shaka, "Ultrahighquality NOE spectra," Journal of the American Chemical Society, vol. 116, no. 13, pp. 6037-6038, 1994.

[22] K. Stott, J. Stonehouse, J. Keeler, T.-L. Hwang, and A. J. Shaka, "Excitation sculpting in high-resolution nuclear magnetic resonance spectroscopy: application to selective NOE experiments," Journal of the American Chemical Society, vol. 117, no. 14, pp. 4199-4200, 1995.

[23] T.-L. Hwang and A.-J. Shaka, "Water suppression that works. Excitation sculpting using arbitrary waveforms and pulsed field gradients," Journal of Magnetic Resonance, Series A, vol. 112, no. 2, pp. 275-279, 1995.

[24] M. J. Frisch, G. W. Trucks, H. B. Schlegel et al., Gaussian09, Revision A.01, Gaussian, Wallingford, Con, USA, 2009.

[25] Y. Zhao and D. G. Truhlar, "The M06 suite of density functionals for main group thermochemistry, thermochemical kinetics, noncovalent interactions, excited states, and transition elements: two new functionals and systematic testing of four M06-class functionals and 12 other functionals," Theoretical Chemistry Accounts, vol. 120, no. 1-3, pp. 215-241, 2008.

[26] Y. Zhao and D. G. Truhlar, "Density functionals with broad applicability in chemistry," Accounts of Chemical Research, vol. 41, no. 2, pp. 157-167, 2008.

[27] K. Wolinski, J. F. Hinton, and P. Pulay, "Efficient implementation of the gauge-independent atomic orbital method for NMR chemical shift calculations," Journal of the American Chemical Society, vol. 112, no. 23, pp. 8251-8260, 1990.

[28] A. D. Becke, "Density-functional thermochemistry. III. The role of exact exchange," Journal of Chemical Physics, vol. 98, no. 7, pp. 5648-5652, 1993.

[29] C. Lee, W. Yang, and R. G. Parr, "Development of the ColleSalvetti correlation-energy formula into a functional of the electron density," Physical Review B, vol. 37, no. 2, pp. 785789,1988 . 


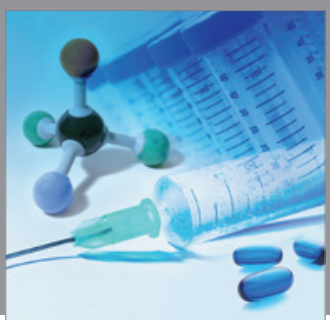

International Journal of

Medicinal Chemistry

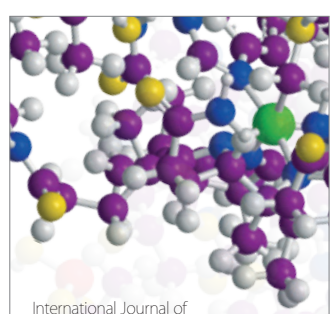

Carbohydrate Chemistry

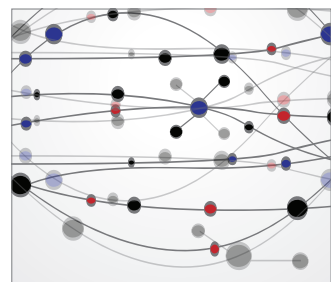

The Scientific World Journal
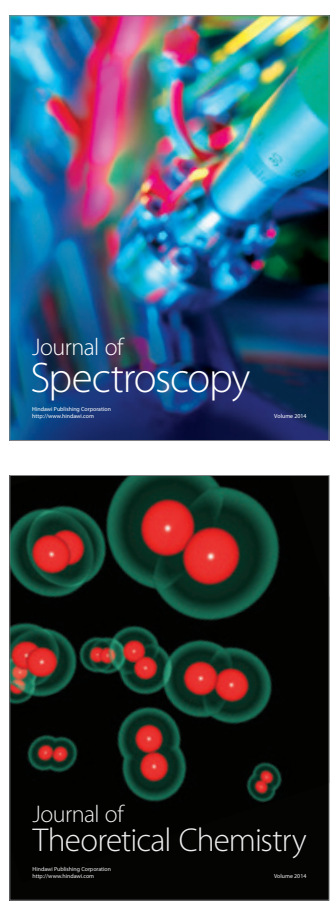
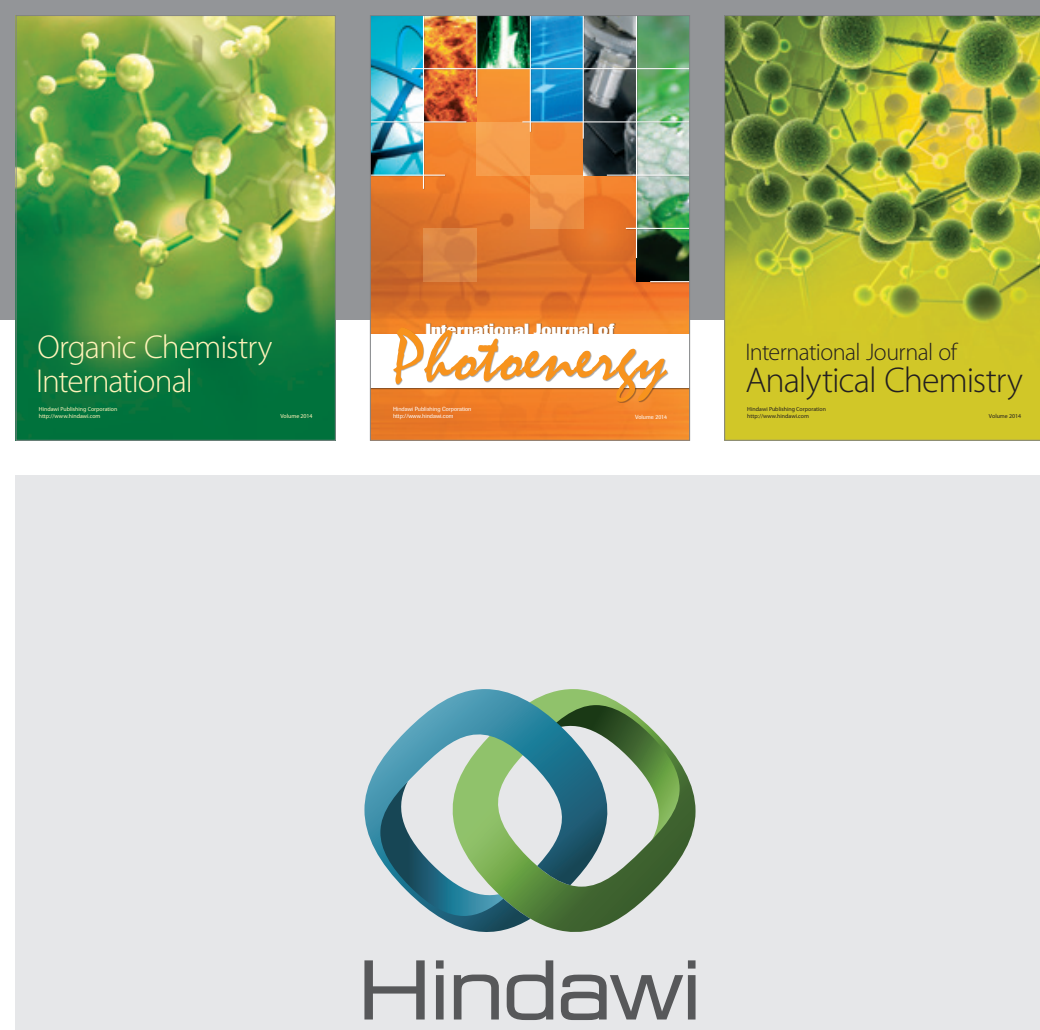

Submit your manuscripts at

http://www.hindawi.com
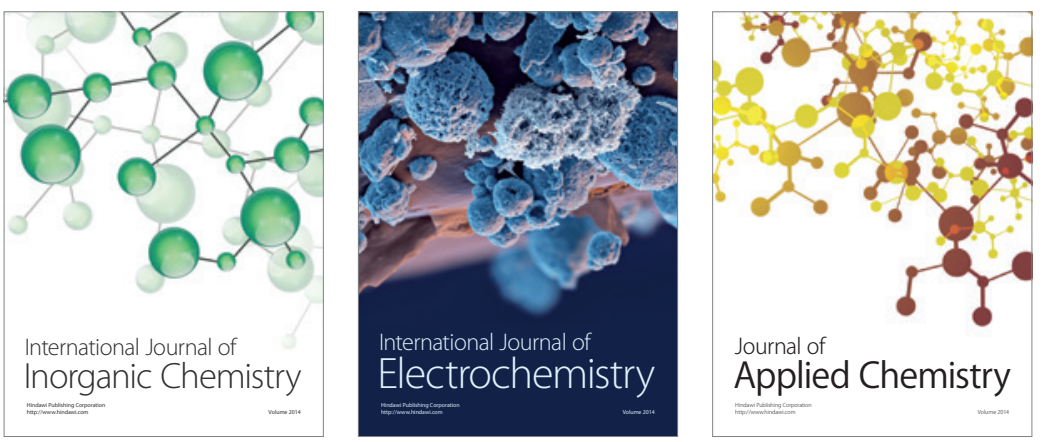

Journal of

Applied Chemistry
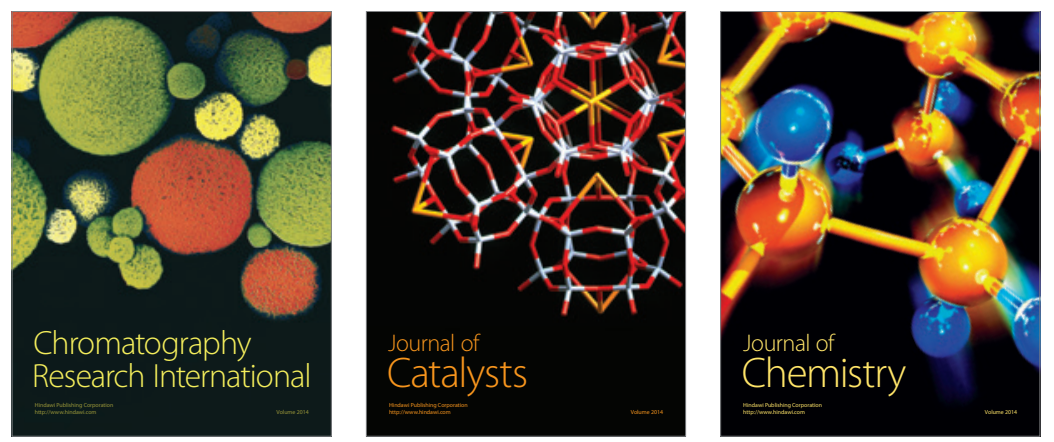
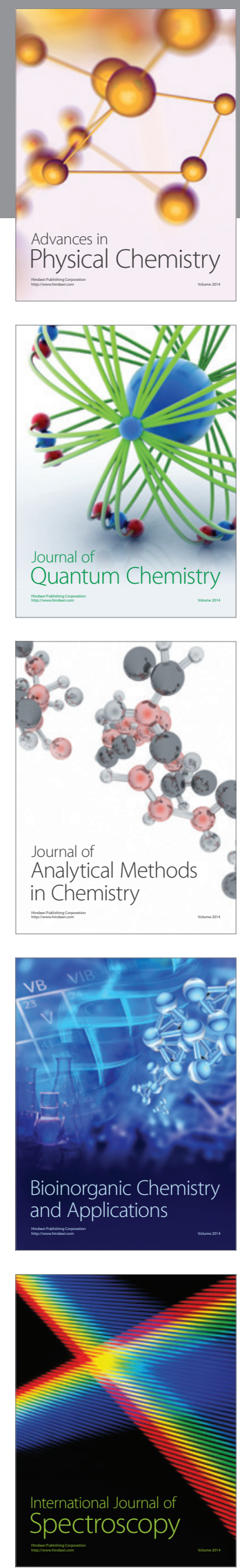